Thomas L. Ely, DO, Ray L. Morrison, DO and David L. Broder, DO

\title{
Official Call: 2021 Annual Business Meeting of the American Osteopathic Association
}

https://doi.org/10.1515/jom-2021-9999

Published online April 12, 2021

To the Officers and Members of the American Osteopathic Association and the Presidents and Executive Directors of AOA Affiliates (Divisional, Specialty and Non-practice):

The 2021 Annual Business Meeting of the Board of Trustees and Annual House of Delegates (HOD) of the American Osteopathic Association (AOA) will be held July 12-18, 2021.

\section{AOA Board of Trustees Meeting}

The AOA Board of Trustees (BOT) will convene for its annual business meeting from July $12-14$ at AOA headquarters in Chicago. The New AOA BOT will meet on July 18. The BOT meeting agenda and all other meeting-related information will be available on the AOA BOT portal at least ten (10) business days prior to the start of the meeting.

\section{AOA House of Delegates Annual Meeting}

The AOA House of Delegates (HOD) will convene its annual meeting Friday, July 16, and conclude on
Sunday, July 18 . The meeting will take place on a virtual platform.

The resolution process last year was reformatted to improve the quality of the content provided to the delegates, which required an expansion of the time for resolution processing. Therefore, the resolution processing timing will be consistent with the timeframe last year.

The resolution deadline for this year is Friday, May 7. Despite the fact that this is an early submission deadline, the notification date offers more time for resolution submission than has been previously provided.

All resolutions must be submitted electronically to resolutions@osteopathic.org. Resolutions will not be accepted after the submission process closes on Friday, May 7. However, "LATE RESOLUTIONS" received after the deadline will be reviewed by the HOD Rules \& Order of Business Reference Committee, which will determine whether the resolution will be considered by the 2021 HOD. "LATE RESOLUTIONS" will be considered only if the delay is due to circumstances that make submission by the deadline impossible. Resolutions should not be submitted after the deadline for convenience.

The House of Delegates meeting agenda and all meeting-related materials will be posted to the AOA Annual Business Meeting website 21 days prior to the start of the HOD Meeting.

Thomas L. Ely, DO, Ray L. Morrison, DO and David L. Broder, DO 